\title{
A simple biological marker to differentiate the types of Herpes Simplex Viruses in resource-limited settings
}

\author{
Akter $\mathrm{T}^{1}$, Tabassum $\mathrm{S}^{2}$, Nessa $\mathrm{A}^{2}$, Jahan $\mathrm{M}^{2}$ \\ ${ }^{l}$ Department of Microbiology, Holy Family Red Crescent Medical College, Dhaka, \\ ${ }^{2}$ Department of Virology, Bangabandhu Sheikh Mujib Medical University, Dhaka, \\ Email:doctor_taslima11@yahoo.com
}

\begin{abstract}
Herpes simplex viruses (HSV) multiply readily on the chorioallantoic membrane (CAM) of embryonated hen's egg and produce easily visible foci or pocks on this membrane. In the present study, pocks produced by the two antigenic types of HSV $(1 \& 2)$ were compared to evaluate the effectiveness of typing HSV isolates by pock size on CAMs. A total of $57 \mathrm{HSV}$ isolates from both non-genital and genital samples were typed by the pock size produced on the CAMs of fertile hen's eggs. Twenty two HSV isolates yielded visible pocks on CAM, of which 9 (40.9\%) produced small pocks, while $13(59.1 \%)$ produced large pocks. All pocks produced on CAM were confirmed by antigenic typing by the Direct Fluorescent Antibody (DFA) method. HSV isolates which produced small pocks were in complete (100\%) concordance with HSV type-1, while those producing larger pocks were in full (100\%) concordance with HSV type-2. Thus, the pock size on CAM of embryonated fertile hen's egg may be used as a simple and relatively inexpensive biological marker for the differentiation of HSV types $1 \& 2$.
\end{abstract}

\section{Introduction}

Herpes simplex virus (HSV) can be differentiated antigenically into two groups, types $1 \& 2$. Type- 1 is generally associated with non-genital infections while type- 2 is commonly associated with genital infections, although both types may cause similar diseases at both anatomical sites ${ }^{1}$. However, the frequency of reactivation of HSV is influenced by anatomic site and the type of virus ${ }^{2}$. Genital HSV-2 infection is twice as likely to reactivate and recurs 8-10 times more frequently than genital HSV-1 infection. Conversely, oral-labial HSV-1 infection recurs more frequently than oral-labial HSV-2 infection $^{3}$. It is therefore important to identify the type of HSV which cause herpetic (herpes labialis or genital herpes) infections as this influences prognosis and treatment recommendations ${ }^{4}$. Moreover, typing of HSV influences counseling of patients ${ }^{5}$.

A number of biological and serological methods are available to differentiate HSV types $1 \& 2$. Among these, certain biological tests are more amenable to routine diagnostic virology procedures than serological tests used to determine antigenic differences. Some techniques, e.g., buoyant density determination ${ }^{6}$, infectivity titers in different cell cultures $^{7}$ and inoculation of HSV into animals such as mice ${ }^{8}$ are research techniques requiring special equipments, facilities, or excessive supplies for a diagnostic laboratory. The same applies to the use of Vero cells in which type-2 HSV were markedly inhibited at temperatures greater than $39^{\circ} \mathrm{C}$, whereas type-1 HSV replicated easily at 39.8 to $40.3^{\circ} \mathrm{C}^{9}$. Other techniques, such as determination of cytopathic effect on a variety of cell cultures may be rather subjective ${ }^{10}$.

Herpes simplex virus multiplies readily on the chorioallantoic membrane (CAM) of embryonated hen's egg and produces easily visible foci or pocks on this membrane ${ }^{11}$. Many investigator were able to differentiate these two types of herpes simplex viruses by measuring the size of pocks on CAM. Larger pocks produced on CAMs has been associated with type $2 \mathrm{HSV}$ and smaller pocks with type-1 $\mathrm{HSV}^{12-16}$. In the present study, clinical samples were used to determine the relationship of pock size on CAM with the two antigenic types of HSV isolates.

\section{Materials and Methods}

This randomized study was conducted at the Department of Virology, Bangabandhu Sheikh Mujib Medical University (BSMMU) from July 2008 to June 2009. Samples were collected from vesicular and non-vesicular lesions of 57 clinically 
diagnosed herpetic lesions (genital and non-genital) by polyester-tipped applicators. After collection, the swabs were immediately immersed in $1 \mathrm{ml}$ of Eagle's minimal essential medium containing 400 $\mathrm{U} / \mathrm{ml}$ of Penicillin, $100 \mu \mathrm{g} / \mathrm{ml}$ of Gentamycin, 10 $\mu \mathrm{g} / \mathrm{ml}$ of Amphoterecin-B and $2 \%$ fetal bovine serum. The specimens were frozen at $-70^{\circ} \mathrm{C}$ temperatures within 30 minutes of collection.

For egg inoculation, $0.1 \mathrm{ml}$ of specimen was inoculated on the CAM of 10-12 days old embryonated hen's egg using the false air sac technique ${ }^{17}$. Each sample was inoculated into 3 eggs. Known type-1 and type-2 strains were included as control. After incubation in the egg incubator (Mashalles, Type G-180, Spain) at $37^{\circ} \mathrm{C}$ for 3 and 5 days, the CAMs were harvested. The harvested membranes were placed in a Petridish containing normal saline to detect the characteristic lesions or pocks. The size of the pocks was estimated with an ocular micrometer mounted on a light microscope. Pock size was divided at $3^{\text {rd }}$ day of inoculation into two groups based on the following criteria: ${ }^{12}$

Small pocks: Commonly produced by HSV-1, having an average diameter less than $0.5 \mathrm{~mm}$.

Large pocks: Commonly produced by HSV-2, with average diameter greater than $0.5 \mathrm{~mm}$.

On the $5^{\text {th }}$ day, pock size which becomes larger as compared to $3^{\text {rd }}$ day were designated as HSV-2, but those that remained typically small were dsignated as $\mathrm{HSV}-1^{14}$. Measurement of pocks were taken before antigenic typing.

For antigenic typing of HSV, membranes were ground with mortar and pestle in PBS ( $\mathrm{pH} 7.3)$ and spotted onto a slide for identification and typing of HSV by the direct fluorescent antibody method (DFA) (Pathfinder HSV type-I \& type-2, Biorad, India, Cat no-25215). A positive immunofluorescence result was indicated by the presence of one or more intact cells exhibiting typical appearance of apple green fluorescence. Typing was determined by the appearance of a specific fluorescent reaction with one of the monoclonal antibodies. HSV-1 infected cells showed cytoplasmic staining, while HSV-2 infected cell showed both cytoplasmic and nuclear staining.

\section{Results}

Out of the total 57 samples tested, 22 isolates produced visible pocks on the CAMs, of which 14 $(63.6 \%)$ isolates were obtained from genital sites and $8(36.4 \%)$ were obtained from non-genital sites.
Of the 14 samples from genital sites, 13(92.9\%) produced large pocks on the CAM at $3^{\text {rd }}$ day with an average diameter of $0.5-0.9 \mathrm{~mm}$ (Fig-1) and become larger $(2-3 \mathrm{~mm})$ at $5^{\text {th }}$ day (Fig-2). Only one $(7.1 \%) \mathrm{HSV}$ isolate produced small pocks $(<0.5 \mathrm{~mm})$ at $3^{\text {rd }}$ day and its size remained typically small at $5^{\text {th }}$ day. All 13 genital isolates which produced large pocks were confirmed as HSV-2 by DFA method while only one genital isolates which produced small pock was confirmed as HSV-1 by the DFA method (Table-I).

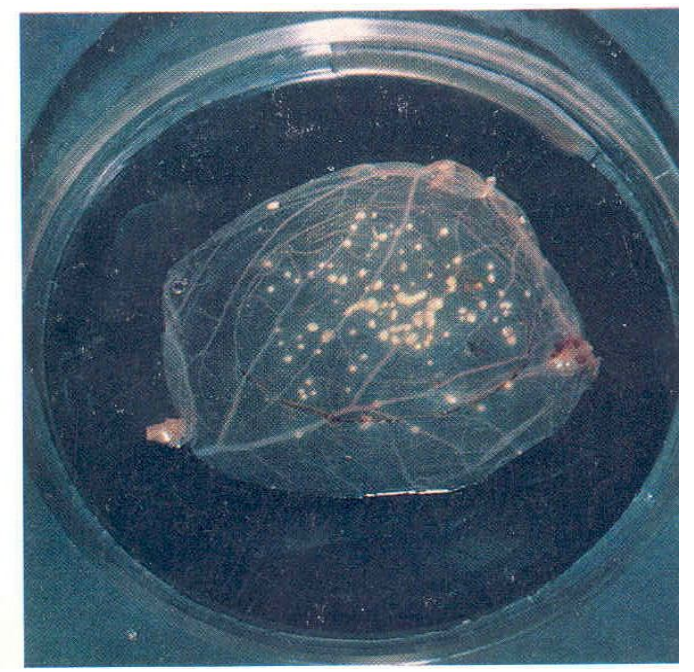

Fig-1: Pock produced by HSV-2 on $3^{\text {rd }}$ day.

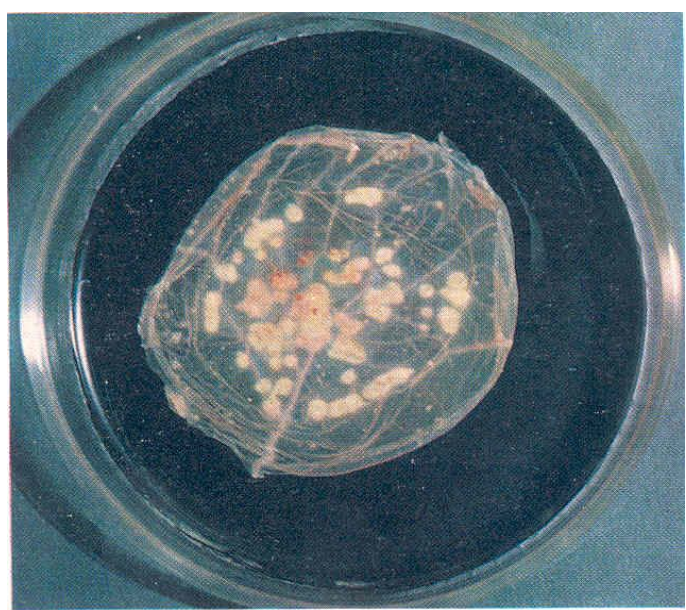

Fig-2: Pocks produced by HSV-2 at $5^{\text {th }}$ day (size has increased).

Table-I: Results of typing genital isolates of HSV by size of pocks and DFA method

\begin{tabular}{ccccc}
\hline Sex & $\begin{array}{c}\text { No. of } \\
\text { isolates } \\
(\mathrm{n}=14)\end{array}$ & Site of lesion & $\begin{array}{c}\text { Size of } \\
\text { pocks on } \\
\text { CAM }\end{array}$ & $\begin{array}{c}\text { Type of } \\
\text { HSV (by } \\
\text { DFA test })\end{array}$ \\
\hline M & 3 & Inside urethra & Large & Type-2 \\
M & 4 & Shaft of penis & 3 Large & Type-2 \\
& & Glans penis & Large & Type-1 \\
Type-2 \\
F & 3 & Vagina & Large & Type-2 \\
F & 1 & Vulva & Large & Type-2 \\
\hline
\end{tabular}


Out of the 8 isolates obtained from extra-genital sites, all produced small pocks at $3^{\text {rd }}$ day with an average diameter of $0.2-0.5 \mathrm{~mm}$ (Fig-3) and showed no change in size of lesion at $5^{\text {th }}$ day (Fig4). On typing of non-genital isolates in relation to pock size, all were confirmed as $\mathrm{HSV}-1$ by the DFA method (Table-II).

Thus, a total of $9(40.9 \%)$ samples were identified as HSV type-1 and $13(59.1 \%)$ as HSV type-2 according to size of pocks on the CAM of embryonated hen's egg.

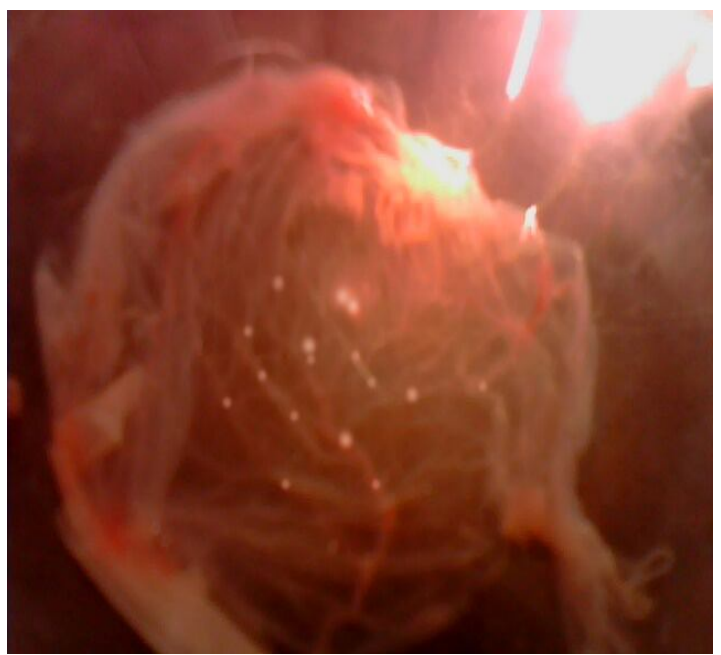

Fig-3: Pock produced by HSV-1 on $3^{\text {rd }}$ day.

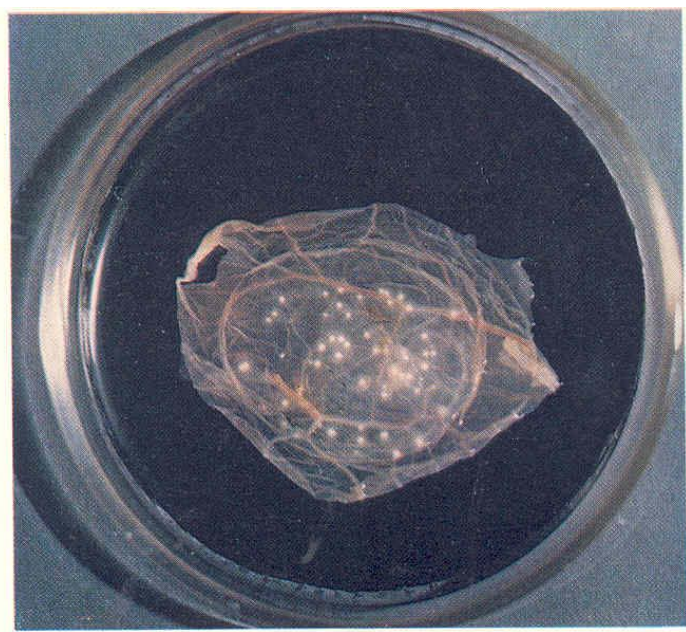

Fig-4: Pocks produced by HSV-1 at $5^{\text {th }}$ day (size remained same).

Table-II: Results of typing of non-genital isolates of HSV by size of pocks and DFA method.

\begin{tabular}{ccccc}
\hline Sex & $\begin{array}{c}\text { No of } \\
\text { isolates } \\
(\mathrm{n}=8)\end{array}$ & Site of lesion & $\begin{array}{c}\text { Size of } \\
\text { pocks on } \\
\text { CAM }\end{array}$ & $\begin{array}{c}\text { Type of } \\
\text { HSV (by } \\
\text { DFA test) }\end{array}$ \\
\hline F & 4 & Herpes labialis & Small & Type-1 \\
F & 2 & Acute gingivostomatitis & Small & Type-1 \\
M & 1 & Herpetic whitlow & Small & Type-1 \\
M & 1 & Herpes labialis & Small & Type-1 \\
\hline
\end{tabular}

\section{Discussion}

It is possible to type HSV isolates by their capacity to produce different pock sizes on CAMs. The present study sought to demonstrate the relationship of pock size with the two antigenic types of HSV isolated from clinical samples of both genital and non-genital sites. Our study observed that almost all $(92.9 \%) \mathrm{HSV}$ isolates from genital lesions produced large pocks on the CAM, which were confirmed by the more reliable DFA method as HSV-2. Only one (7.1\%) HSV isolate from a genital lesion produced small pocks and was confirmed by DFA test as HSV-1. On the other hand, all non-genital lesions produced small pocks and were confirmed by DFA test as HSV-1. A similar study from USA reported that most of the pocks produced by HSV-2 exceeded $1 \mathrm{~mm}$ in diameter at $3^{\text {rd }}$ day ${ }^{12}$. This was probably because the work was done with high passage laboratory strains rather than low passage clinical isolates, since repeated passage of HSV isolates tend to diminish the distinctive properties of the two types by means of selection and mutation. Another study from the UK which had adopted HSV isolates by egg passage first reported that the size of pocks produced by HSV-2 were $0.8-1 \mathrm{~mm}$, while HSV-1 were $0.2-0.5 \mathrm{~mm}^{18}$, which is comparable to our findings. Similarly, other studies to differentiate HSV isolates from clinical samples by pock size observed that pocks produced by HSV-2 isolates were comparatively larger $(>0.5 \mathrm{~mm})$ while $\mathrm{HSV}-1$ were smaller $(<0.5 \mathrm{~mm})^{15,17}$.

Furthermore, our study observed that if CAMs are inspected at 5 days rather than at 3 days, larger lesions (2-3 $\mathrm{mm}$ in diameter) occurred with HSV-2 isolates, whereas, HSV-1 isolates remained typically small. Similar findings have been reported earlier ${ }^{14}$. This may be another significant determinant for the differentiation of HSV-1 and HSV-2.

Our study found the method of typing HSV isolates on CAM as very accurate. The technique employed for the study was relatively simple as eggs are readily available and also quite cheap. Moreover, inoculation on CAM is an easy procedure in comparison to other biological methods such as virus culture, and results can be obtained within 3 days. Therefore, in resource poor settings, the pock test on CAM of embryonated hen's egg may be used as a quick, easy, reliable and inexpensive biological marker to ascertain the antigenic types of HSV from clinical samples. 


\section{References}

1. Smith C. Herpes Simplex Virus. Retrieved March 12, 2007 from http://www.abc.net.au/health/library/stories/ 2005/05/05/183/2287.htm.

2. Lafferty WE, Coombs RW, Benedetti J, Critchlow C, \& Corey L. Recurrences after oral and genital herpes simplex virus infection. N Engl J Med 1987; 316: 1444-1449.

3. Corey L, Adams HG, Brown ZA, \& Holmes KK. Genital herpes simplex virus infection, clinical manifestations, course, complication. Ann Intern Med 1983; 98: 958-72.

4. CDC. Department of Health and Human Service. Sexually transmitted diseases: treatment guidelines 2006. Retrieved November, 21, 2007 from http:// www.cdc.gov/std/treatment/2006/genital-ulcers.htm.

5. Singh A, Jutta P, Frenczy, \& Barbare R. The laboratory diagnosis of herpes simplex virus infection. Can $\mathbf{J}$ Infect Dis Med Microbiol 2005; 16 (2): 1-11.

6. Goodheart C, Plummer G, \& Waner J. Density difference of DNA of human herpes simplex viruses type I and II. Virology 1968; 35: 473-475.

7. Plummer G, Waner JL, \& Bowling CP. Comparative studies of type 1 and type 2 herpes simplex viruses. Br. J. Exp. Pathol. 1968; 49: 202-208.

8. Mogensen SC, Teisner B, \& Anderson HK. Focal necrotic hepatitis in mice as biological marker for differentiation of Herpes virus hominis type 1 and type 2. J Gen Virol 1974; 25: 151-155.

9. Rafcliffe H. Differentiation of herpes simplex virus type 1 and type 2 by temperature markers. J Gen Virol 1971; 13: 181-183.
10. Figueroa M, \& Rawls W. Biological markers for differentiation of herpes-virus strains of oral and genital origin. J Gen Virol 1969; 4: 259-267.

11. Cox HR. Growth viruses and Rikettsiae in the developing chick embryo. Ann New York Acad Sci 1952; 55(2): 236-247.

12. Nahmias AJ, Dowdle WR, Naib ZM, Highsmith A, Harwell RW, \& Josey WE. Relation of pock size on chorioallantoic membrane to antigenic type of Herpesvirus hominis. Proc Soc Exp Biol Med 1968; 127: $1022-1028$.

13. Hutfield DC. Isolation studies with genital strains of herpes simplex virus. Acta Dermato-venereologica 1967; 47: 118-122.

14. Parker JDJ, \& Banatvala JE. Herpes genitalis: Clinical and virological studies. Br J Venereal Dis 1967; 43: 212-216.

15. Marks-Hellman S, \& Ho M. Use of biological characteristics to type herpes virus homonis type-1 and 2 in diagnostic laboratories. J Clin Microbiol 1976; 3: 277-280.

16. Russell WC. A sensitive and precise plaque assay for herpesvirus. Nature 1962; 195: 1028-1029.

17. World Health Organization (WHO). Guide to the laboratory diagnosis of small pox eradication programs 1969; Geneva: pp. 28-43.

18. Herrod HA, Mclean B, Hambling MH, \& Halliburton IW. Efficiency of the use of pock size on the chorioallantoic membrane of fertile hen's egg as a method of typing herpes simplex virus. J Hyg 1984; 93: 95-103. 